\title{
La mirada de Morrow sobre México: ¿preludio de la Buena Vecindad?
}

\author{
Maria del Carmen Collado Herrera \\ INSTITUTO MORA
}

Se aborda la gestión diplomática de Dwight W. Morrow en México utilizando el enfoque de la historia cultural. Se pone énfasis en la percepción de este embajador sobre su vecino del sur como ingrediente para explicar el giro de las relaciones entre México y Estados Unidos. Se sostiene que su mirada de formó en las intersecciones del discurso del dominado y el dominante, en una etapa en que la contracultura estadunidense revaloraba "al otro", representado por el latinoamericano.

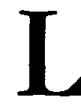

a gestión diplomática de Dwight Whitney Morrow (1927-1930) ha llamado la atención de diversos estudiosos por el drástico giro que logró dar a la diplomacia de ambos países. Previo a su nombramiento, aquélla se encontraba empantanada, después de haber transitado por uno de los momentos más ásperos de la etapa posrevolucionaria. El reflujo reformista que vivía la administración de Calles, sumado a la habilidad del embajador, posibilitó un cambio en las relaciones bilaterales, enfilándolas hacia la negociación y dejando atrás los estériles enfrentamientos.
Durante sus tres años al frente de la embajada estadunidense, Morrow consiguió resolver varias de las cuestiones que preocupaban al Departamento de Estado como la controversia petrolera, el conflicto entre la Iglesia y el Estado y frenar el reparto agrario. No obstante, ninguna de estas soluciones fue definitiva y en relación con la reestructuración de la deuda externa mexicana, su proyecto principal no logró ningún acuerdo. Pese a que sus logros fueron coyunturales, Morrow creó un ambiente de cordialidad en la relación de ambos países que probó ser más duradero que su propia gestión. 
Han surgido diversas interpretaciones para explicar esta metamorfosis. El biógrafo de Morrow, Harold Nicolson, sostiene que la ideología liberal del nuevo embajador, la aplicación de su teoría de la "tutela moral" ejercida por los fuertes sobre los débiles, aunadas a sus extraordinarios talentos personales y su habilidad particular para la conciliación, fueron las herramientas que sacaron a la relación bilateral del callejón sin salida en que se encontraba como resultado de la colisión entre el imperialismo y el nacionalismo. ${ }^{1}$ Stanley Ross, pone énfasis en las circunstancias que rodearon el nombramiento de Morrow y la nueva perspectiva desde la cual éste condujo las relaciones con su vecino del sur para explicar el giro de Washington. Entre aquéllas, la influencia de los grupos con intereses comerciales y financieros en México opuestos a la preeminencia de los intereses petroleros en el diseño de la política exterior. Así como las presiones de intelectuales, líderes políticos de oposición, periodistas, dirigentes sindicales y del clero protestante en contra del uso de la fuerza y a favor de la adopción de medidas pacíficas. Éstas derivaban -de acuerdo con el autor citado- de la pervivencia del concepto wilsoniano liberal de la autodeterminación de las naciones; y se sumaron a la escasa disposición del público estadunidense a respaldar una intervención que, desde su perspectiva, impulsaban los petroleros, muy desacreditados por el escándalo del Teapot Do$m e .^{2}$ Para Lorenzo Meyer, el cambio se

\footnotetext{
${ }^{1}$ Nicolson, Dwight, 1935, pp. 295-296.

${ }^{2}$ Ross, Morrow, 1958, pp. 275-276.
}

gestó en la propia Casa Blanca, que ante los nulos éxitos de su política en México y la oposición que ésta había generado en círculos del Senado, como "quizá por influencia tanto de los banqueros como de la opinión pública nacional", optó por una nueva línea diplomática. ${ }^{3}$ En un artículo posterior, este mismo autor considera que la rotación se debió al nuevo enfoque diplomático de Morrow, pero sobre todo, al cambio de orientación política del gobierno de Calles hacia el centro derecha que lo volvieron más receptivo a las propuestas del estadunidense. ${ }^{4}$ Robert Freeman Smith atribuye la transición a que Morrow representaba la visión de los financieros que, identificada con el desarrollismo impulsado por los sonorenses, se oponía a la intervención y a la política dura que promovían los petroleros atrincherados tras el Departamento de Estado. ${ }^{5}$

Como se puede apreciar, los autores señalados confieren distinto valor a los elementos que explican la mudanza diplomática. ${ }^{\circ}$ Meyer, en el primer trabajo mencionado, y Smith coinciden en subrayar el impacto de los intereses privados en la política exterior de Estados Unidos; en el segundo texto, Meyer analiza el cambio como resultado

${ }^{3}$ Meyer, México, 1981, pp. 266 y 281.

"Meyer, "Dwight", 1998, p. 253.

${ }^{5}$ Smith, Nacionalismo, 1973, pp. 361-362.

${ }^{6}$ Desde luego no menciono la visión que otros autores tienen sobre Morrow, fundamentalmente porque no centran su análisis en el viraje diplomático, sino más bien en las características del gobierno de Calles y el maximato y en la participación del embajador en la política mexicana. Entre otros me refiero a José Vasconcelos, Arnaldo Córdova y Joaquín Cárdenas. 
Hay muy poca sangre blanca en el gabinete $[\ldots]$ Calles es armenio e indio, León, un torero aficionado y casi totalmente indio, el canciller judío e indio, Morones con más sangre blanca, pero no de la mejor, Amaro, el secretario de Guerra, un indio de pura sangre y muy cruel. Disparó a muerte a su mozo de cuadra anteayer por montar, en lugar de guiar, su pony de polo -un incidente atestiguado por al menos un inglés y un estadunidense. Ni se mencionó, por supuesto, en los periódicos, ni hubo castigo alguno. Le cuento esto para que visualice con lo que me enfrento. ${ }^{14}$

No resulta extraño que durante su gestión, este prominente abogado de firmas corporativas, identificado con la vieja guardia del Partido Republicano, haya instado a su gobierno a adoptar una actitud firme y rígida hacia México. Sus prejuicios de superioridad anglosajona se recrudecieron:

Hacía bromas sobre México y en privado ridiculizaba al pueblo. Le horrorizaba el bandidaje, el bandolerismo, el escándalo y el desorden. Le aterraba ver pasar pollos y guajolotes en grupo frente a la embajada. ${ }^{15}$

Su visión sobre la misión de los hijos del Tío Sam en México era que, dada su superioridad económica y de civilización, tenían la obligación moral de "levantar y asentar a estos pueblos retrasados" 16 Su actitud pondría las relaciones de ambos países al borde de la ruptura. 126.

${ }^{14}$ Citado por Ferrell, Presidency, 1998, p.

${ }^{15}$ Horn, "Embajador", 1970, pp. 271-273.

${ }^{16}$ Ibid., p. 272.
Frente al callejón sin salida en que éstas se encontraban las administraciones de ambas naciones retrocedieron y buscaron una salida negociada. Era evidente que Sheffield no era el más indicado para llevar adelante esta misión por lo que el siguiente movimiento de la Casa Blanca fue nombrar a Dwight Morrow, antiguo condiscípulo del presidente en Amherst College y socio de la firma J. P. Morgan \& Co., como embajador en México con la única instrucción de mantener la relación alejada de la guerra. ${ }^{17} \mathrm{El}$ imperialismo de viejo cuño estaba a punto de emprender un viraje. Una carta de Norman Davis a Morrow, escrita pocos días después de su nombramiento, planteaba la encrucijada:

Creo que hemos llegado al periodo más crítico de nuestras relaciones con México. Hemos llegado al punto donde debemos repensar definitivamente si a fin de cuentas queremos o no absorber a México, o decidir positivamente no hacerlo, $y$ ayudar a los mexicanos para que trabajen en su propia salvación. Mientras la tendencia en muchos aspectos es la primera, estoy convencido de que no es la solución más sabia. Además de la cuestión moral y las dificultades inherentes de tratar de incorporar una población extraña, tan grande como la mexicana, un intento por conseguirlo aumentaria gravemente nuestros problemas con el resto de Latinoamérica. Los mexicanos son los más difíciles de tratar de todos los pueblos latinoamericanos, pero me sentiría satisfecho si pudiéramos disipar el temor por parte de México de que pretendemos absorberlo, entonces nuestras relaciones con

${ }^{17}$ Ferrell, Presidency, 1998, p. 129. 
ellos tomarían un giro y podrían conducirse hacia la cooperación bajo un espíritu apropiado para nosotros. Desafortunadamente, la historia de nuestras relaciones con México hace difícil que logremos disipar este gran temor hacia nosotros. Cada vez que hemos tenido un conflicto verdadero han perdido te. rritorio. ${ }^{18}$

Nadie mejor equipado que Morrow para cumplir con esta encomienda. Era el típico self made man, hijo de un maestro y después director del Marshall College, que vivió con limitaciones materiales en su infancia. Ingresó a Amherst College, gracias al apoyo económico que le brindó su cuñado, y a su trabajo, en que enseñaba matemáticas a sus condiscípulos. Posteriormente estudió derecho en la Universidad de Columbia, más tarde ingresó a un prestigioso bufete de abogados neoyorquino y, en 1914, se incorporó a la poderosa firma bancaria J. P. Morgan \& Co., la cual lo hizo socio. Morrow, aunque republicano, era un liberal avanzado, de amplio criterio; no dudaba en criticar las políticas de su partido cuando no las compartía. Tal vez lo más característico de su ideología era la hete-

${ }^{18}$ Carta de Norman Davis a Morrow, 30 de septiembre de 1927 en Amherst College Archives (en adelante ACA) Dwight Morrow Papers 1877-1954, Serie X, Ambassador to Mexico, 1927-1930, microfilme, rollo 2. Norman Davis era un financiero y político demócrata que fue nombrado subsecretario de Estado en 1920 y al año siguiente renunció a este cargo. Tuvo varios nombramientos en comisiones internacionales y fue colaborador de Foreign Affairs. Favoreció el panamericanismo y el desarme y, en 1933, se convirtió en consejero sobre asuntos exteriores del presidente Franklin D. Roosevelt. rodoxia que guiaba su pragmatismo; aunque siempre se mantuvo fiel al Partido Republicano, no adoptó sus posiciones automáticamente; tampoco se le puede catalogar como un progresivista, pese a la laxitud ideológica de este movimiento. ${ }^{19}$

Sus diferencias con el imperialismo tradicional se manifestaron en sus de. claraciones de que no iría a México como cobrador de deudas. Su experiencia financiera le había enseñado, como publicó en un artículo de Foreign Affairs en 1927:

¿Puede haber alguien que piense que si un hombre le debe dinero y no le puede pagar, consiga algún provecho matando al deudor? [...] la guerra en la mayor parte de los casos no logra y no puede lograr el resultado deseado. ${ }^{20}$

Entendía la diplomacia "como el arte de asegurar una cooperación razonable entre los pueblos del mundo."21 La negociación, por medio de la búsqueda de una convergencia de los intereses nacionales de México con los de Estados Unidos, marcaría su labor mexicana, dejando fuera la presión, las amenazas y el enfrentamiento.

Morrow creía que en la igualdad juridica de las naciones debian fincarse las relaciones entre países, por encima de sus asimetrías. De igual manera rechazaba la intervención militar como medio para lograr los fines del imperialismo. ${ }^{22}$ De acuerdo con su biógra-

${ }^{19}$ Véase Jones, Limits, 1983, pp. 368-392. 36-37.

${ }^{20}$ Citado por Howland, Dwigbt, 1930, pp.

${ }^{21}$ Nicolson, Dwight, 1935, p. 225.

${ }^{22}$ Ibid., p. 265. 
fo, Harold Nicolson, tenía un fuerte instinto protector que se manifestó en su teoría de la tutoría moral, la cual suponía que Estados Unidos debía ayudar a los países latinoamericanos a que se levantaran sobre sus pies: una extrapolación de la ideología del self made man al ámbito de las relaciones internacionales. Previo a su nombramiento como embajador tuvo oportunidad de ponerla en práctica cuando, como asesor financiero del gobierno cubano enviado por la Casa Morgan a la isla, manifestó su discrepancia con la Enmienda Platt. ${ }^{23}$ Su teoría de la "tutoría moral" bien podría ser calificada de paternalista, pero no se trataba del paternalismo victoriano colonialista, sino de uno renovado, un poco más distante del racismo y el etnocentrismo; capaz de apreciar las posibilidades "del otro". De una mirada imperialista que, después de lograr un absoluto predominio sobre el hemisferio, surgía de las intersecciones del discurso del dominado y el dominante. ${ }^{24} \mathrm{La}$ cooperación en lugar del avasallamiento probaría ser más útil para abrir los países vecinos a los designios de esta nueva faceta imperial.

En vísperas de su salida hacia México declaró: "Bueno, yo sé una cosa que puedo hacer por los mexicanos, pueden gustarme". ${ }^{25}$ Esta frase sintetizaba su mirada sobre México. Reconocía que el poder y la posibilidad de hacer algo por sus vecinos radicaban en él, representante del Tío'Sam, y, por otro lado, advertía que si éstos le gustaban,

${ }^{23}$ Morrow, Àdress, 1925, p. 4.

${ }^{24}$ Oto, Viaje, 1996, pp. 18 y 27.

${ }^{25}$ McBride, Story, 1930, p. 128. enunciando un deseo que daba por sentada su capacidad de aquilatar lo mexicano, podría abrir a la nación y negociar en mejores condiciones.

En su discurso de presentación con Calles, el abogado de 54 años señaló, con retórica diplomática, su satisfacción por poder "cooperar" con el presidente, y equiparó a México con Estados Unidos por su igualdad como estados soberanos e independientes. ${ }^{26}$ Pero más allá del lenguaje verbal, los gestos del embajador buscaban una mayor cercanía con sus nuevos anfitriones. Asistió a este evento en traje de mañana convencido de que el traje de etiqueta, utilizado por los diplomáticos, no era una costumbre local. ${ }^{27}$ Este gesto buscaba crear una imagen de proximidad, adoptando un uso que él suponía mexicano; dándole a su aspecto sencillez, a fin de originar un efecto que redujera la brecha que separaba a la potencia imperial, de México. Otro gesto que sorprendió y ganó la confianza de Calles se dio durante el primer desayuno privado que sostuvieron, en el cual prescindió del traductor de la embajada y aceptó que el intérprete entre ambos fuera James Smithers, amigo cercano de Calles, quien no había sido bienvenido en la embajada durante la gestión de Sheffield por sus ligas con el presidente. ${ }^{28}$ La confianza y amistad marcarían las relaciones entre ambos pesonajes; $\mathrm{Ca}$ -

${ }^{26}$ Discurso de presentación de Morrow ante Calles, 29 de octubre de 1927 en ACA, Dwight Morrow Papers 1877-1954, serie X, microfilme, rollo 1.

${ }^{27}$ McBride, Story, 1930, p. 130.

.28 Nicolson, Dwight, 1935, p. 316. 
lles al fin conocía a un embajador estadunidense que lo trataba como a un igual, sin aires de superioridad; éste llegaba precisamente en un momento en que se encontraba rodeado de soledad por la proximidad del fin de su mandato.

Pero en el contacto que Morrow establecería con el sonorense no todo eran gestos diplomáticos: aquél se emocionaría desde un principio con sus planes reformistas y reconocería en Calles a un gran estadista. ${ }^{29}$ Las innovaciones mexicanas no eran vistas por Morrow como producto de las inclinaciones de un país incivilizado y al margen de la legalidad internacional, sino como una necesidad derivada de su historia. La confianza que logró sembrar en Calles y otros funcionarios mexicanos, como el canciller Genaro Estrada o el secretario de Hacienda Luis Montes de Oca, sumada a su brillante intelecto, su enorme experiencia en asuntos financieros y la compatibilidad entre el proceso de reconstrucción que impulsaba la administración mexicana con su idea de que el país "volviera a levantarse y caminar con sus propios pies" ${ }^{30}$ fueron fundamentales para con-

\footnotetext{
${ }^{29}$ Memorándum, [s. f.] en ACA, Dwight Morrow Papers 1877-1954, serie $\mathrm{X}$, microfilme, rollo 13.

${ }^{30}$ Carta de Morrow a Lindbergh, 18 de noviembre de 1927 , en ibid., serie $\mathrm{X}$, microfilme, rollo 5. En esta misiva Morrow expresaba: "Mi trabajo aqui se ha desarrollado maravillosamente. Las buenas relaciones con los funcionarios gubernamentales continúan y creo que ellos empiezan a sentir que no tengo intenciones ulteriores, sino que lo que realmente deseo es ayudarlos a volver a levantarse y caminar con sus propios pies y que inicien un periodo de, paz y prosperidad."
}

vertirlo en asesor informal del presidente y le permitieron adentrarse en los más íntimos círculos del poder. ${ }^{31}$

Otro elemento que destaca de su concepción sobre la política exterior de Estados Unidos era la necesidad de desvincularla de los intereses privados y sustentarla en una visión más amplia de los intereses nacionales a fin de no embrollarla en los conflictos de un grupo particular de inversionistas. Morrow percibía que el interés nacional ${ }^{32}$ de su país representaba a una amplia gama de grupos económicos: banqueros, comerciantes, industriales, petroleros y productores agrícolas. Por ello su política exterior no debía cons-trenirse a la defensa de un sector en particular, sino sustentarse en una visión del conjunto que, además, contemplara los intereses geoestratégicos vitales del país.

Con respecto a los petroleros que no aceptaban estos cambios apuntó:

Los últimos seis meses han sido toda una revelación para mí por el grado en que compañías petroleras de responsabilidad parecen creer que es deber del Departamento de Estado hacerse cargo, de sus negocios en tierras extranjeras.

${ }^{31}$ En el archivo de Morrow se encuentran numerosas evidencias de esto. Frecuentemente aparecen notas sobre aspectos como el religioso, el petrolero, el agrario o el financiero en el que el embajador sugiere el contenido de las declaraciones al presidente. Véase, ACA, Dwight Morrow Papêrs 1877.1954, serie X.

${ }^{32}$ Retomamos el concepto de ińterés nacional desarrollado por Reynolds y Roseneau. Véase, Reynolds, Introducción, 1977, pp. 49-59, y Roseneau, Scientific, 1971, p. 249. 
iNunca hubiera creído que esto fuera posible! ${ }^{33}$

En cuanto a su relación con la colonia estadunidense en México, se deslindó de la actitud de Sheffield, quien al involucrarse fundamentalmente con este grupo, integrado en su mayoría por hombres de negocios, abogados, profesionistas y altos funcionarios de compañías estadunidenses, adoptó muchas de sus discrepancias con México como causas diplomáticas. Morrow puso en claro que su embajada estaba acreditada frente al gobierno mexicano, no frente a la colonia estadunidense en la ciudad de México. Esta advertencia resultó de las críticas que suscitó entre algunos de sus miembros el acercamiento franco y directo que mantuvo con el presidente Calles desde sus primeras entrevistas. Por ello, durante un discurso que pronunció ante los residentes estadúnidenses, el 19 de noviembre de 1927 subrayó:

En el largo plazo las relaciones entre dos grandes países vecinos como Mé. xico y Estados Unidos descansan fundamentalmente en lo que ustedes hacen como enviados extraoficiales. Estados Unidos será interpretado en México por sus actos. Si pudiera dejarles un pensamiento sería el expresado por el secretario Root, cuando visitó México hace veinte años: "Ustedes no sólo representan su país, sino que tienen el deber de actuar a favor del país en el que viven. Al tiempo que prosigan siendo ciudadanos estadunidenses buenos y

${ }^{33}$ Carta de Morrow a Olds, 8 de mayo de 1928 en ACA, Dwight Morrow Papers 1877 1954, serie $\mathrm{x}$, microfilme, rollo 8 . leales, deben ser residentes mexicanos buenos y leales". ${ }^{34}$

Indudablemente la apariencia del nuevo embajador, quien paseaba por Chapultepec en las mañanas, gozaba de asistir a los mercados, comprar artesanías y recorrer los poblados, despertaba simpatía. Su pequeña talla, la informalidad de su vestimenta y su sonrisa a flor de piel no parecían corresponder con la imagen que los mexicanos se habían forjado de un representante del poderoso vecino. Esta simpatía contribuyó a allanar las anteriores dificulcades.

La "leyenda negra" y el desprecio por la herencia española se encontraban lejos del embajador. ${ }^{35}$ El reconocimiento de los valores de "la otredad" manifestado en Morrow en varias oportunidades, estaba influido por la valorización de las culturas latinoamericanas promovida por los representantes de la contracultura estadunidense en los años veinte. desarrolló un gran afécto por lo mexicano. En su correspondencia con amigos solía invitarlos a visitar el país,

34 "Common sense ignores hysterics", News Bulletin, núm. 3, vol. vII, 25 de noviembre de 1927 , en $i$ bid., serie $\mathrm{X}$, microfilme, rollo 4

${ }^{35}$ Ello se manifiesta en el discurso que dio al presidente electo cubano Machado en Nueva York en 1925. Véase Morrow, Adress, 1925 , pp. 6-7.

${ }^{36}$ Pike, United, 1992. Este autor asegura que inicialmente los estereotipos por los cuales los pueblos "civilizados" juzgaban a los "pueblos en estado de naturaleza" nacieron de las actitudes de los colonizadores británicos hacia los indios y los esclavos negros, y que más adelante estas actitudes fueron transferidas a los latinoamericanos. 
poniendo énfasis en las virtudes de estas tierras extrañas a la mirada anglosajona.

Muy poca gente entiende qué país maravilloso es México. La Florida, Cuba, el sur de California y el resto de los lugares de invierno están muy por detrás de México. El clima es perfecto y las cosas por conocer no tienen duplicado en ningún lugar de la tierra. Así lo vea uno por el lado de la vieja civilización azteca o de la vieja civilización española es un país interesante de estudiar. ${ }^{37}$

En el verano de 1928 los Morrow emprendieron la construcción de una casa en Cuernavaca, enamorados de la belle. za del paisaje, de la ciudad y de sus pobladores. La bautizaron como Casa Mañana porque durante su construcción, el maestro de obras respondía indefectiblemente a las preguntas de Morrow sobre cuándo estaría lista tal o cual cosa: "Mañana, señor embajador, mañana". ${ }^{38}$ Su aprecio por la cultura popular se manifestó en esta residencia de descanso, edificada con"paredes de adobe, techada con tejas y totalmente decorada con artesanías nacionales que los señores Morrow compraban: sarapes en lugar de alfombras; bordados y jícaras de Michoacán y Olinalá colgaban en las paredes en vez de cuadros. Las vajillas eran de barro y los vasos de vidrio soplado. "Nunca pude resistir un jarro que dijera 'Luz de mis ojos' o 'Adiosito querida Lolita", cuenta la se-

${ }^{37}$ Carta de Morrow a Bruce Barton, 3 de febrero de 1928, en ACA, Dwight Morrow Papers 1877-1954, serie X, microfilme, rollo 1 .

${ }^{38}$ Presentación de Adriana Estrada Cajigal en Morrow, Casa, 1982, p. 5. ñora Morrow..$^{39}$ En uno de los patios se construyó una cocina mexicana al aire libre con su tradicional decoración de jarros y cazuelas vidriadas en el muro. Uno de los patios era llamado el Jardín Secreto, porque

su entrada estaba completamente oculta, cubierta por una enredadera de Gloria, éste tenía una fuente de azulejos amarillos y azules en un extremo y una "loggia" cubierta en el otro extremo, donde el cònde Reneé d'Harnoncourt, nuestro amigo austríaco, pintó "Una vista panorámica de la muy bella y hermosa ciudad de Cuernavaca" según lo anunciaba un listón sostenido por gordos querubines en la parte superior del cuadro. La ciudad entera estaba en ese fresco, comenzaba en nuestra calle, y nuestro viejo constructor indígena [Pancho Rebollo] con su overol azul, en un extremo del mismo, descorría una cortina a la manera del siglo XVII, descubrien. do la casa que él había creado. ${ }^{4()}$

El fresco evoca las artes decorativas populares mexicanas e incorpora el listón con el nombre de la pintura, retomando un recurso del arte colonial utilizado frecuentemente por Diego Rivera y Frida Kahlo: ${ }^{41}$ Sin duda los Morrow también participaban del estereotipo romántico de lo indígena, característico de la contracultura estadunidense que adquirió relevancia a raíz de la gran depresión. ${ }^{42}$ Cuando Elizabeth Morrow recuerda en Casa Mañana la reticencia de un carpintero cuer.

\footnotetext{
${ }^{39}$ Ibid., p. 11.

${ }^{40}$ Ibid.

${ }^{41}$ Herrera, Frida, 1998, p. 111

${ }_{22}$ Pike, United, 1992, p. 244 y Delpar, Enormous, 1992, pp. $62-63$ y 68 .
} 


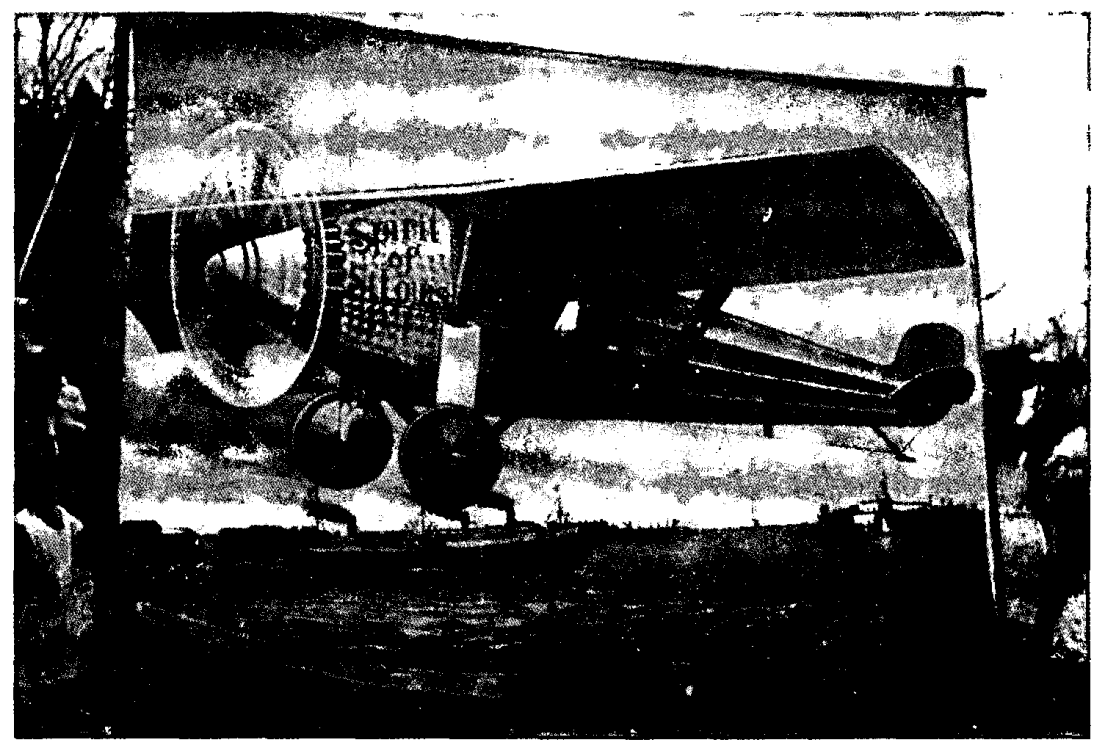

navaquense a hacerle 12 sillas, en vez de vendérselas una por una, en lugar de ver un defecto en el talante de este indígena, lo aprecia como una virtud al señalar:

Éste es un ejemplo perfecto de la actitud del artesano y trabajador mexicano hacia todo lo que hace. Es la antítesis de nuestro sentimiento de producción en masa, el cual despreciaría si pudiera entenderlo. El ama el jarro, el juguete, el zarape [sic] que sostiene en sus manos, no se apresura a terminarlo y siempre le dará un toque, algo de sí mismo. Esto constituye el encanto y la desesperación de amueblar una casa en México. ${ }^{43}$

${ }^{43}$ Morrow, Casa, 1982, p. 19.
Pero su admiración por lo mexicano no se restringió a la cultura popular, también se sintió atraído, como tantos otros extranjeros, por la Escuela Mexicana de Pintura. Dwight Morrow compró lienzos a estos autores. ${ }^{44}$ En una cena que él y su esposa compartieron con Diego Rivera y Frida Kahlo le pidió al muralista que pintara un fresco sobre una de las galerías del Palacio de Cortés en Cuernavaca. A través de William Spratling, otro amigo suyo quien permanecería definitivamente en Taxco dedicándose al diseño de plata, le mandó el anticipo. El costo total del mural sería de 12000 pesos; el emba-

${ }^{44}$ Brenner, Viento, 1975, pie de página de la fotografia 144. 
jador pidió a Diego y a Genaro Estrada que su mecenazgo se mantuviera en secreto. ${ }^{45}$ La simpatía entre ambos matrimonios fue tal que los señores Morrow le prestaron su casa de Cuernavaca a la entonces recién casada pareja para facilitar a Rivera el desarrollo de su trabajo, pues ellos se trasladaron a Londres a la Conferencia Naval de 1930 y luego a Estados Unidos para promover la campaña del entonces embajador al Senado, ausentándose del país durante casi seis meses. ${ }^{46}$ El fresco muestra la brutalidad de la conquista y la heroica gesta revolucionaria, en la cual $\mathrm{Za}$ pata ocupa un lugar destacado montado sobre un caballo blanco. ${ }^{47}$ Cuando Diego aceptó el encargo del embajador hacía dos meses que había sido expulsado del Partido Comunista, como resultado del giro ultraizquierdista que tomó a partir del VI Congreso de la Comitern. ${ }^{48}$

Morrow fue el primer representante de su país en aquilatar la importancia de las relaciones culturales como coadyuvante de la diplomacia. Su primer expe-

45 Carta de Morrow a Diego Rivera, 5 de diciembre de 1929, microfilme, rollo 8 , y carta de Ambrosio Puente a Morrow, 30 de diciembre de 1929, microfilme, rollo 3, en ACA, Dwight Morrow Papers 1877-1954, serie X.

${ }^{46}$ Herrera, Frida, 1998, p. 96-97. Según esta autora ocuparon la casa de los Morrow durante un año, pero ellos regresaron a México en junio de 1930.

${ }^{47}$ Ibid., p. 97.

${ }^{48}$ Carr, Izquierda, 1996, p. 56-57. La expulsión se fundamentó en las desviaciones "pe. queño burguesas" del pintor y en su colaboración con un gobierno "reaccionario", aceptando comisiones para decorar edificios públicos que creaban la imagen de un régimen liberal y tolerante. Véase Herrera, Frida, 1998, p. 94. rimento en este sentido fue la invitación que extendió a Charles Lindbergh para que volara a México, después de su hazaña cruzando el Atlántico en el Spirit of St Louis. ${ }^{49}$ Pensaba que la visita del héroe de la aviación no sólo promovería la buena voluntad, sino que distraería a los mexicanos de sus problemas. ${ }^{50} Y$ no se equivocó, la recepción al "rey de la aviación", como lo llamó la prensa mexicana, fue verdaderamente apoteósica. Se calcula que alrededor de 125000 personas lo recibieron en Balbuena y sus alrededores, muchas de las cuales pasaron la noche en vela para ganar un buen lugar. Miles de capitalinos siguieron paso a paso sus itinerarios en la ciudad de México; desde las calles, las azoteas, las copas de los árboles y las torres de catedral. Sin duda, la visita del futuro yerno de Dwight constituyó un gran éxito diplomático, desdibujando de la mente pública los enfrentamientos que el gobierno mexicano había tenido con el Tío Sam pocos meses antes; llegaba en momentos, como bien lo había advertido él, en que la incertidumbre nublaba las vidas de los mexicanos, quienes tenían poca oportunidad de diversión por la difícil situación económica del país, la guerra cristera, el cierre de los templos y la violencia que acompañaba la oposición a la campaña reeleccionista de Obregón. ${ }^{51}$

${ }^{49}$ Carta de Morrow a Lindbergh, 18 de noviembre de 1927, en ACA, Dwight Morrow Papers 1877-1954, serie X, microfilme, rollo 5 .

${ }^{50}$ McBride, Story, 1930, p. 135.

51 Reyes, "Tumultuosa", 1995, pp. 202, 210. 213. Apenas dos meses antes de su viaje, los mexicanos se habían conmocionado por la matanza de Huitzilac en la que perdieron la vida el 
Morrow también estimuló la publicación de artículos informados sobre México, promovió las giras de la Orquesta Típica por Estados Unidos ${ }^{52} \mathrm{e}$ impulsó el turismo. ${ }^{53}$ Pero sus tareas de promoción cultural no quedaron allí. Él y su esposa entablaron amistad con Frances Flynn Paine, una de las impulsoras del arte mexicano en Estados Unidos. La señora. Morrow formó parte del cuerpo de directores de la Mexican Arts Corporation, asociación no lucrativa fundada por Paine en 1930. En este organismo también eran directivos John D. Rockefeller, su esposa Abby Aldrich y su cuñado el banquero Winthrop W. Aldrich. Dwight Morrow concibió la idea de montar una gran exposición de arte popular, artes aplicadas y plástica mexicanas, con el apoyo de la Carnegie Corporation de Nueva York, con objeto de familiarizar al público estadunidense con las manifestaciones artísticas de su vecino sureño. Gracias a su sugerencia, se encargó a Reneé de Harnoncourt reunir las piezas y realizar la museografía. La exposición fue inaugurada con gran éxito el 13 de octubre de 1930 en el Museo Metropolitano de Nueva York. Se exhibieron más de 300 objetos que abarcaban desde el periodo colonial hasta el contemporáneo; 24 pintores mexicanos estuvieron representados con obras, entre ellas pinturas de Orozco, Rivera, Mérida, Charlot, Tamayo, Covarrubias, Rodríguez Lozano, Clausell y Revueltas. La

general Francisco Serrano y un puñado de sus seguidores opuestos a la reelección del ex presidente Obregón.

${ }^{52}$ Ross, Morrow, 1958, p. 281.

${ }^{53}$ McBride, Story, 1930, p. 151. exposición viajó a Boston, Pittsburgh, Washington, Louisville y San Antonio. Se estima que alrededor de 450000 personas la visitaron. ${ }^{54}$

La mirada de Morrow hacia México fue un ingrediente importante en su gestión diplomática, le permitió acercarse a la administración revolucionaria, quien gracias al carácter conservador que adquiriría a partir de 1927 , se mostró a su vez dispuesta a aplicar las reformas sugeridas por el estadunidense. A diferencia de sus antecesores, quienes dirigieron sus esfuerzos hacia la salvaguarda primordial de los intereses de sus connacionales, el antiguo funcionario bancario, sin descuidar aquéllos, se preocupó porque México consiguiera un crecimiento estable que garantizara la paz, constituyéndose en un espacio seguro para los inversionistas y que no amenazara los designios estratégicos de Estados Unidos en Centroamérica y el Caribe. De ahí su interés por solucionar el problema petrolero, el enfrentamiento entre la Iglesia y el Estado, frenar la reforma agraria, y arreglar las finanzas mexicanas, aunque en este último asunto no consiguió éxito, tanto por la crisis económica mundial, y los excesivos gastos militares del gobierno, como por las reticencias que hacia él mostraba el nuevo presidente Pascual Ortiz Rubio. ${ }^{55}$

\footnotetext{
${ }^{54}$ Delpar, Enormous, 1992, pp. 144-145.

55 Éste desconfiaba del embajador por su cercanía con Calles; además le irritaron las palabras que el coronel Alexander Macnab, ex agregado militar de la embajada, pronunció en Newark durante la campaña senatorial del todavía embajador quien señaló: "No existe un departamento del gobierno en México que él no haya
} 
Morrow echó mano de la negociación en lugar del enfrentamiento a partir de los puntos de coincidencia entre los intereses nacionales de ambos países; optó por caminos prácticos que resolvieran los desacuerdos sin dar demasiada importancia a la terminología legal; trató de ejercer una diplomacia que no representara los intereses de un sector económico en particular, sino que se fincara en los intereses nacionales de mayor alcance. Esto, desde luego, le valió críticas de los petroleros y lo llevó a disentir con sus antiguos socios de J. P. Morgan sobre la manera de reestructurar el pago de la deuda externa. Probablemente, Morrow se convirtió en uno de los embajadores más poderosos del México contemporáneo, gracias a la influencia que logró tener sobre Calles y otros funcionarios del Maximato.

Sin duda la mirada de Morrow sobre México correspondía a un nuevo estilo imperialista, teñido de paternalismo, surgido en las intersecciones del discurso de la potencia imperial y el mexicano. Su carácter amistoso, su simpatía por las cosas mexicanas y el fortalecimiento del intercambio cultural como herramienta diplomática marcaron el inicio de una nueva etapa en las relaciones bilaterales. Morrow trans-

asesorado o guiado. Puso al Secretario de Hacienda bajo su protección y le enseñó finanzas." Nicolson, Dwight, 1935, p. 382. Cuando el embajador regresó a México, después de meses de ausencia por su participación en la Conferencia Naval de Londres y su campaña por un puesto en el Senado como representante de Nueva Jersey, las condiciones políticas habían variado y ya no gozaría de la influencia que tuvo durante las gestiones de Calles y Portes Gil. mitió al Departamento de Estado una visión distinta al estereotipo tradicional del México revolucionario no civilizado, al margen de la legalidad occidental. Representa sin duda una fase novedosa del discurso imperial en la que éste ya no sólo buscaba avasallar, ${ }^{56}$ sino que también deseaba conocer al otro y era capaz de apreciarlo; de un distanciamiento de la diplomacia dura, característica de los primeros años de la década de los años veinte, y un barrunto de la que florecería bajo el gobierno de Franklin D. Roosevelt, en la cual prominentes representantes de la cultura alternativa se convirtieron en funcionarios del régimen. ${ }^{57} \mathrm{El}$ estilo diplomático de Dwight Morrow constituyó un preludio de la política de la Buena Vecindad: los fines no variaron, cambiaron los medios.

\section{ARCHIVOS}

-Amherst College Archives, Dwight Morrow Papers 1877-1954. Serie X, Ambassador to Mexico, 1927-1930. (Microfilmes en la Biblioteca del Instituto Mora.)

\section{BIBLIOGRAFÍA}

-Brenner, Anita, El viento que barrió a México. Historia de la revolución mexicana

${ }^{56}$ Meyer, Historia, 1978, p. 194. Este autor lo señala de la siguiente manera: "Así, las reglas formales del juego político interamericano - particularmente importantes para México- cam. biaron dramáticamente entre 1927 y 1934. El predominio estadunidense era indiscutible, pero precisamente por eso no hacía falta que se manifestara con la brutalidad del pasado."

${ }^{57}$ Véase Pike, United, 1992, cap. 8. 
1910-1942, traducción de María Dolores de la Peña, Gobierno del Estado de Aguascalientes, Aguascalientes, 1975.

-Carr, Barry, La izquierda mexicana a través del siglo $x X$, Ediciones Era, México, 1996.

-Delpar, Helen, The enormous vogue of things mexican. Cultural relations between the United States and Mexico, The University of Alabama Press, Tuscaloosa, 1992.

-Ferrell, Robert H., The presidency of Calvin Coolidge, University of Kansas Press, Kansas, 1998.

-Findling, John E., Dictionary of american diplomatic bistory, 2a. edición corregida y aumentada, Grenwood Press, Nueva York, 1989.

-Herrera, Hayden, Frida: una biografía de Frida Kablo, 19a. reimp., Editorial Diana, México, 1988.

-Horn, James J., "El embajador Sheffield contra el presidente Calles", Historia Mexicana, El Colegio de México, vol. Xx, núm. 78 , octubre diciembre de 1970 , pp. 265-284, México.

-Howland, Hewitt H., Dwight Whitney Morrow: a sketch in admiration, introducción de Calvin Coolidge, Century Company, Nueva York, 1930.

-Hunt, Michael H., "Ideology", The Journal of American History, vol. 77, núm. 1, junio de 1990, pp. 108-115.

-Jones, Maldwyn A., The limits of liberty. American bistory 1607-1980, Oxford University Press, Nueva York, 1983.

-McBride, Mary Margaret, The story of Dwight W. Morrow, Farrar \& Rinehart Incorporated, Nueva York, 1930.

-Meyer, Lorenzo, "Dwight W. Morrow (1927-1930)" en Ana Rosa Suárez (comp.), En el nombre del Destino Manifiesto. Guia de ministros y embajadores de Estados Unidos en México, Instituto Mora/Secretaría de Relaciones Exteriores, México, 1998, pp. 249-255.
Rafael Segovia y Alejandra Lajous, Historia de la revolución mexicana, periodo 1928-1934. Los inicios de la institucionalización. La política del Maximato, El Colegio de México, México, 1978. México y Estados Unidos durante el conflicto petrolero, 1917-1942, El Colegio de México, 3a. reimp., México, 1981.

-Morrow, Dwight W., Adress of Dwight W. Morrow presiding at the public dinner to president-elect Machado of Cuba [s. e.], Nueva York, 1925.

-Morrow, Elizabeth, Casa Mañana, traducción y presentación de Adriana Estrada Cajigal, Suma Morelense, Cuernavaca, 1982.

-Nicolson, Harold, Dwight Morrow, Harcourt, Brace and Company, Nueva York, 1935.

-Oto, Alejandro J. de, El viaje de la escritura. Richard F. Burton y el este de Africa, El Colegio de México, México, 1996.

-Pike, Frederick, B., The United States and Latin America. Myths and stereotypes of civilization and nature, University of Texas Press, Austin, 1992.

-Reyes, Aurelio de los, "La tumultuosa bienvenida a Lindbergh, el 'Niño Fidencio' y el éxito de Rey de Reyes, iexpresión de la persecución religiosa en México? (1925. 1927)" en Arte y violencia, XVII Coloquio internacional de bistoria del arte, Instituto de Investigaciones Estéticas-UNAM, México, 1995.

-Reynolds, P. A., Introducción al estudio de las relaciones internacionales, Editorial Tecnos, Madrid, 1977.

-Roseneau, James N., The scientific study of foreign politics, The Free Press, Nueva York, 1971.

-Ross, Stanley, D. W. Morrow, ambassador to Mexico, Academy of American Franciscan History, Washington, 1958.

-Smith, Robert Freeman, Los Estados Unidos y el nacionalismo revolucionario, 1916-1932, Editorial Extemporáneos, México, 1973 (Colección Pleno Sol, 27). 


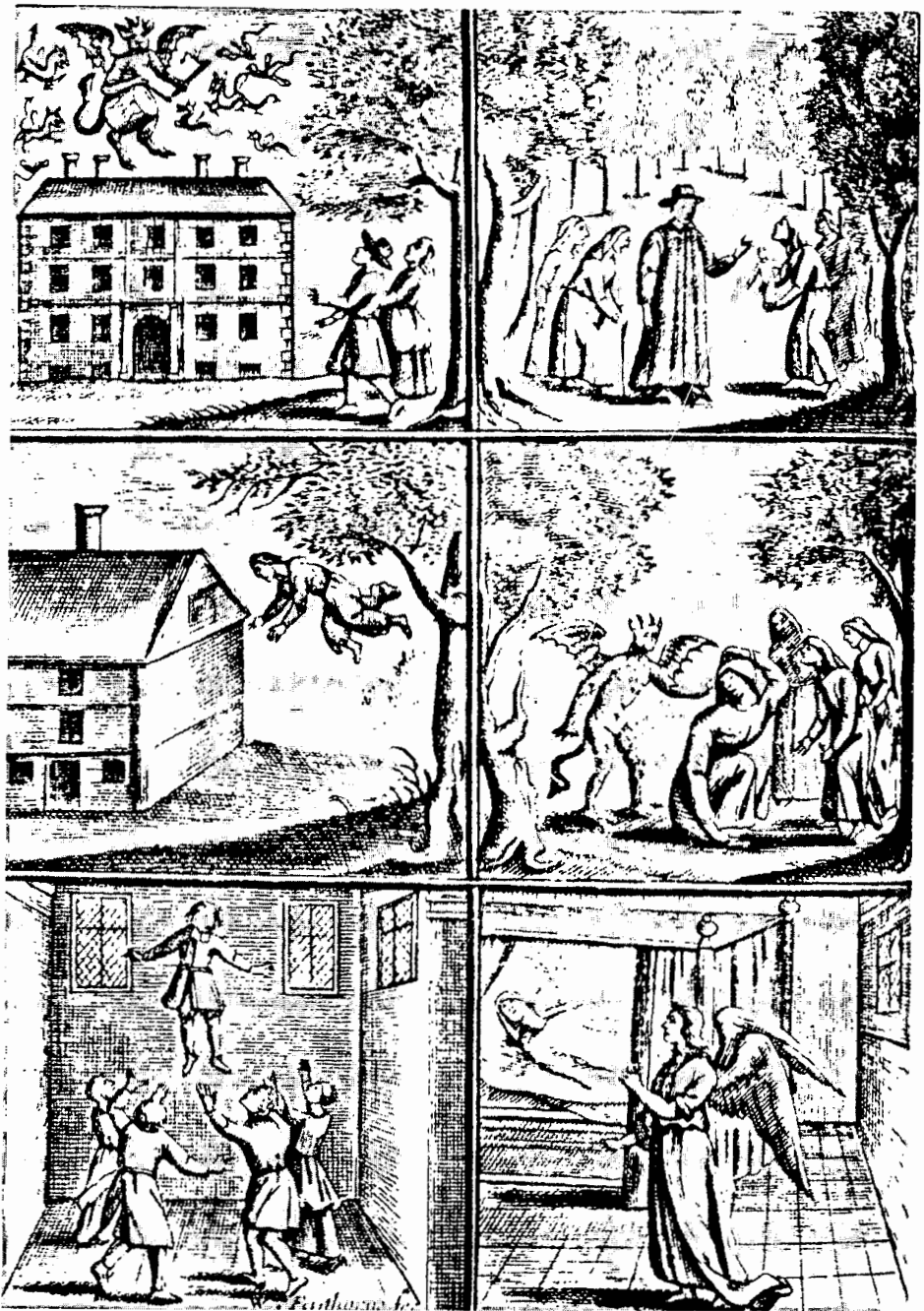

